\title{
Nursing Care for a Patient with NSTEMI Admitted to the Coronary Care Unit for Percutaneous Coronary Intervention - A Case Study
}

\author{
M.S. SITI MARYATI ${ }^{1}$ AND R. (II) P. DIOSO ${ }^{2 *}$
}

\begin{abstract}
This case study aims to demonstrate clinical nursing skills to a patient with myocardial infarction admitted for percutaneous coronary intervention. Nursing care for this patient started with a physical assessment and laboratory investigation analysis. This evaluation was necessary to develop a nursing care plan. The activities in the ward enumerated the medications provided, and the details of the vital signs monitored hourly. The patient was sent to cardiac catheter laboratory at $1030 \mathrm{H}$. From the cardiac catheter laboratory post-percutaneous coronary intervention to the mid-right coronary artery (1 Drug-Eluting Stent) he was transferred out to Telemetry unit on 11 August 2016 at $1500 \mathrm{H}$ with Terumo band hemostatic device through radial approach.
\end{abstract}

Key words: Case study; myocardial infarction; angioplasty; percutaneous coronary intervention; coronary care unit; nursing care; NSTEMI

This case study aims to demonstrate clinical nursing skills to a patient with myocardial infarction admitted to a private hospital in the Kingdom of Saudi Arabia for percutaneous coronary intervention. This intervention is formerly known as angioplasty with stent (Granato, 2011; Badimon et al. 2012); and is a non-surgical procedure that opens up blood vessels in the heart that have been narrowed by atherosclerosis (NSTEMI 2014).

Before commencing with the study, approval from the ward manager of the coronary care unit and the patient was acquired. The hospital used in this case has 700-bed capacity, while the coronary care unit has ten beds, with excellent facilities for patients with heart diseases. Information herewith will be treated with anonymity and confidentiality.

\section{Case Description}

Mr. F is a 41-year-old male, who was scheduled for percutaneous coronary intervention on 10 August 2016 due to non-ST-elevation myocardial infarction (NSTEMI). He is a known diabetic, a hypertensive patient who denies of smoking addiction. His latest Troponin I (0.094) and initial electrocardiography (Appendix 1) was secured. Mr. F's demographic profile is further enumerated in Table 1.

The authors will provide care, management and treatment for the patient at the coronary care unit. However, it is essential to describe the management for the patient that was primarily done at the emergency room.

\footnotetext{
${ }^{1}$ Sulaiman Al Habib Hospital, Arrayan, Riyadh KSA

${ }^{2}$ Lincoln University College, Jalan SS 6/12, 47301 Petaling Jaya, Malaysia

* Corresponding author (e-mail: duke@lincoln.edu.my)
} 
Table 1. Demographic profile.

\begin{tabular}{l|l}
\hline Age & \multicolumn{1}{l}{$\begin{array}{l}\text { Mender } \\
\text { Marital Status }\end{array}$} \\
Nationality & Married \\
Religion & Saudi Arabian \\
Occupation & Muslim \\
Address & Businessman (wholesale trade) \\
Social history & Riyadh, Kingdom Saudi Arabia \\
Height & Heavy smoker (2-3 packs/day) \\
Weight & $\begin{array}{l}165 \mathrm{~cm} \\
\text { Past medical history }\end{array}$ \\
& $\begin{array}{l}\text { Retrosternal compressing type of chest pain with dyspnea and } \\
\text { pain unrelated to exertion. Known diabetic and hypertensive }\end{array}$ \\
Surgical plan & Percutaneous coronary intervention to mid-right coronary artery \\
\hline
\end{tabular}

At $0037 \mathrm{H}, 10$ hours before his schedule for admission to the coronary care unit, Mr. F came to the emergency room on wheelchair borne, with complaints of a retrosternal compressing type of chest pain that lasted for two days intermittently with waxing and waning intensity. On 9 August at $1300 \mathrm{H}$, he experienced a sudden onset of pain, and crescendo over the day (10 to 12 hours before arriving at the hospital) and was associated with sweating, fatigue, and dyspnea - important assessments for nurses to recognize as an impending cause of sudden death among patients with heart diseases (Mozarelli et al. 2011; Badimon et al. 2012). Within the periods of emergency room confinement, vital signs were monitored hourly (Appendix 2). The patient was then transferred to the coronary care unit at 0200 .
Mr. F was immediately seen by Dr M in the coronary care unit to intuitively decide whether an open heart surgery was necessary or proceed with the previous plan of having a percutaneous coronary intervention. The authors (being the attending nurse-in-charge) secured previous blood investigations (Table 3), and echocardiogram results (Table 4). Dr M also prescribed oral medications such as Juspirin $300 \mathrm{mg}$ and Plavix $300 \mathrm{mg}$ per tablet (Table 5) before a decision is finalized. The patient was instructed to rest the whole night.

After 6 hours (at $0800 \mathrm{H}$ ) at the coronary care unit of medical management at the coronary care unit (Appendix 3), the pain subsided. With this assessment cue, the patient can be prepared for a percutaneous coronary intervention. 
In preparation for a percutaneous coronary intervention, the patient was instructed to be on NPO (Nil per orem). An intravenous (IV) fluid of 0.9 normal saline solution at 100 milliliters (mls) /hour was started and received an IV infusion of nitroglycerin at $5 \mathrm{mcg} / \mathrm{min}$ for his mild chest pain (NSTEMI 2014) at around $0230 \mathrm{H}$, and titrated the nitroglycerine infusion according to his blood pressure to maintain systolic pressure at 100 to $120 \mathrm{~mm} \mathrm{Hg}$ until $0600 \mathrm{H}$ as one time dose. All laboratory results were also secured.

This case can be further understood if the altered physiology is explained and an anatomical animation is illustrated. Analyzing the pathway of the disease process in addition to the anatomical and physiological analysis can be useful to provide nurses an excellent care plan.

\section{Altered Anatomy and Physiology}

The NSTEMI of Mr. F is an incomplete heart attack and also one type of myocardial infarction (Granato 2011). An anatomical disturbance of blood supply to a part of his heart (Figure 1) was identified by an elevation of cardiac markers
(Table 2) in the blood (Anderson et al. 2011; Granato 2011). The anatomical structure of the heart can have an enlarged dimension (Shehab et al. 2013; Al Habib et al. 2011).

The absence of ST-segment elevation in NSTEMI is comprehended to implicate less than a full thickness (partial thickness) damage of heart muscle according to Buck (2012). Hence, NSTEMI is a less extreme kind of heart attack in which partial thickness damage of the myocardium (Figure 1) develops.

\section{Pathway of the Disease Process of NSTEMI}

The disease process starts with the growth form of cell death without ST-segment changes (Granato 2011). Figure 1 shows a partial closure or blockage of a major coronary artery or a complete blockage of a minor coronary artery heretofore affected by atherosclerosis (Mozarelli et al. 2011). The most common mechanism of NSTEMI is rupture or erosion of an atherosclerotic plaque that triggers platelet adhesion, activation, and aggregation, which bring to establishment of a thrombus (Figure 1) in a coronary artery, thereby increasing platelet count (Mc Pherson et al. 2011).

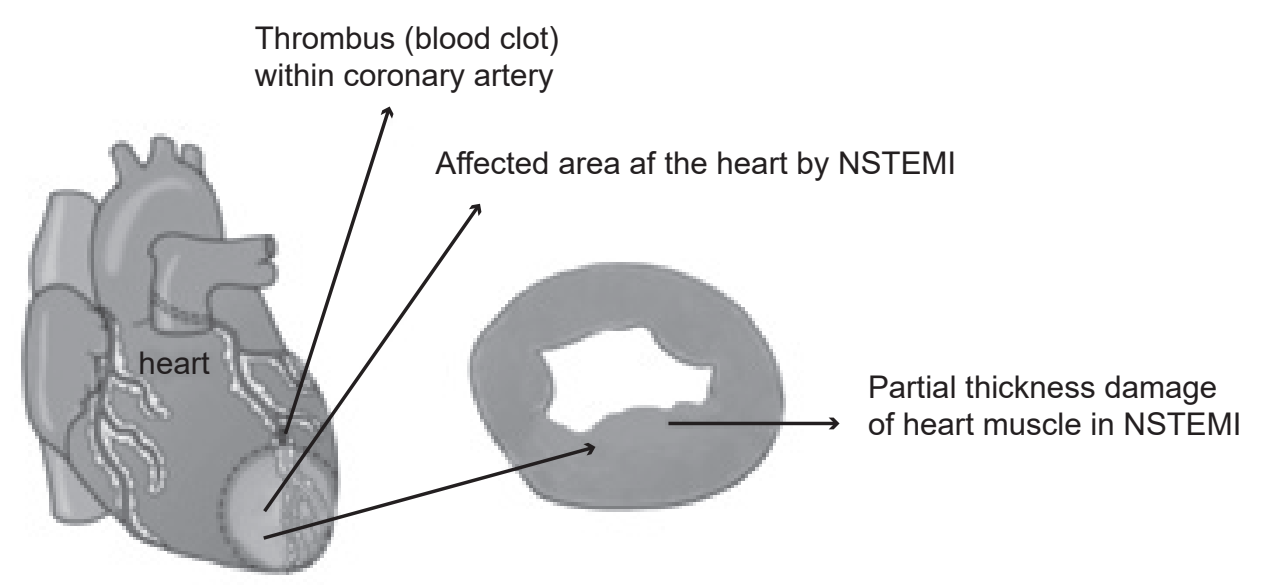

Figure 1. Partial thickness damage of heart muscle in NSTEMI. 
Partial thickness damages of the heart muscle will happen (Badimon et al. 2012). Mc Pherson et al. (2011) agreed that arterial thrombus will develop, and deep changes will take place in the heart that leads to an irreversible change with the death of myocardial cells.

According to Levy et al. (1992), plaque will be removed by percutaneous coronary intervention. However, a thorough laboratory investigation is required to identify an occurrence of a disease on the patient concretely.

\section{Laboratory Results}

Electrocardiography (ECG) (Appendix 1) shows a consistent regular heart rhythm with a total heart rate of $75-85$ beats per minute. There were no ST segment elevation seen in leads V1 and V2 validating the diagnosis of NSTEMI; while the small Q inferior waves noted on leads II, III, and AVF describes infarction in the myocardium. The rest of the ECG tracing shows the PR interval to be normal that was followed by a QRS and every QRS complexes is preceded by a $\mathrm{P}$ wave. This means that the patient prognosis is good and activities of daily living can be tolerated even on post percutaneous coronary intervention status. The LAA (left atrial abnormality) showing an $\mathrm{m}$-shaped (notched) and widened $\mathrm{P}$ wave ( $\geq 0.12$ second) in a "mitral" lead (I, II, and aVL) were also important to note - a deep negative component to the $\mathrm{P}$ wave in lead V1 (P Mitrale) showing the ability of the heart muscle to tolerate surgery. The QT/QTc interval (404/430 milliseconds) were calculated in leads II and V5; while the QRS complex was calculated to be 80 milliseconds which means there were no loss of heart voltage noted, and that the electrical activity of the heart remains rhythmic. The T-wave flattening in amplitude is a sign of an electrolyte imbalance that is why blood specimens need to be sent for serum laboratory investigation (Table 2).

The chest X-ray was also done for heartlung clearances. The result shows that both lung fields were clear and were in costophrenic angles. Mr. F had normal cardiac size and shape and the disease process of NSTEMI that may lead to an enlarged heart did not occur.

The abnormalities found in the serum laboratory results were the delta-dimer, sodium, chloride, white blood cells, platelets, and hemoglobin A1Cs; while the lipid profile such as the cholesterole, triglyceride, and low-density lipoprotein were also altered. This blood/ serum investigation would provide a concrete evidence on the patient's disease occurrence. Also medications to maintain physiologic homeostasis of Mr. F was validated by the blood results such as anti-coagulators (due to high platelet count) and anti-cholesterol (due to abnormal lipid profile). Standard results of the hemoglobin and hematocrit are good evidence that is necessary to be investigated before invasive procedures are done.

Howerver, it is also important to perform an echocardiogram (Table 3) and a coronary angiogram (Table 4) since the chest $\mathrm{X}$-ray and ECG are not able to identify abnormalities (if any) of the heart regions and its chambers in multiple dimensions.

Echocardiography (Table 3) has an advantage unlike the ECG as it has 2 to 3 -dimensional imaging seen by way of 
ultrasonogram without the cardiac cycle (Shehab et al. 2013; AlHabib et al. 2011). In addition, this procedure also provides information on blood movements inside cardiac structures and on haemodyamics (Vincent et al. 2011; Kipshidze et al. 2014; Doenges et al. 2014).
The result of the echocardiography concludes that the percutaneous coronary intervention will hence focus on the left ventricle specifically in the inferio-posterior wall from base to apex of the heart where the blockage was found.

Table 2. Blood serum laboratory investigation.

\begin{tabular}{|c|c|c|}
\hline Serum & Normal value & Result \\
\hline $\begin{array}{l}\text { Serial cardiac enzymes } \\
\text { - Creatinine } \\
\text { - CPK-MB } \\
\text { - CPK } \\
\text { - Troponin I } \\
\text { - Delta-dimer }\end{array}$ & $\begin{array}{l}\cdot 62-106 \\
\cdot<25 \\
\cdot-20-200 \\
\cdot<0.028 \\
\cdot 0.05\end{array}$ & $\begin{array}{l}\bullet 70 \\
\bullet 15 \\
\cdot 151 \\
\cdot 0.094 \\
\bullet 0.39\end{array}$ \\
\hline $\begin{array}{l}\text { Electrolytes } \\
\text { - Sodium } \\
\text { - Urea } \\
\text { - Potassium } \\
\text { - Creatinine } \\
\text { - Chloride }\end{array}$ & $\begin{array}{l}\cdot 135-145 \\
\cdot 2.78-8.07 \\
\cdot 3.5-5.1 \\
\cdot 62-106 \\
\text { - } 98-107\end{array}$ & $\begin{array}{l}\text { - } 180 \\
\text { - } 3.30 \\
\text { - } 4.12 \\
\text { - } 70 \\
\text { - } 70\end{array}$ \\
\hline $\begin{array}{l}\text { Complete blood count } \\
\text { - WBCs } \\
\text { - Neutrophils } \\
\text { - NEUT \% } \\
\text { - Lymphocytes } \\
\text { - LYM \% } \\
\text { - Hemoglobin } \\
\text { - Hematocrit } \\
\text { - MCV } \\
\text { - MCH } \\
\text { - MCHC } \\
\text { - RDW } \\
\text { - Platelets } \\
\text { - Hemoglobin A1C }\end{array}$ & $\begin{array}{l}\cdot 4-11 \\
\cdot 2-6.9 \\
\text { - } 37-80 \\
\text { - } 0.6-4 \\
\text { - } 10-50 \\
\text { - } 13-17.4 \\
\text { - } 39-52 \\
\text { - } 78-96 \\
\text { - } 27-32 \\
\text { - } 29-37 \\
\text { - } 11.6-15.5 \\
\text { - } 150-450 \\
\text { - } 4.8-5.9 \\
\end{array}$ & $\begin{array}{l}\text { - } 9.11 \\
\text { - } 5.31 \\
\text { - } 58.20 \\
\text { - } 2.59 \\
\text { - } 28.40 \\
\text { - } 15.0 \\
\text { - } 41.1 \\
\text { - } 83.0 \\
\text { - } 30.3 \\
\text { - } 36.5 \\
\text { - } 11.7 \\
\text { - } 300 \\
\text { - } 6.96 \\
\end{array}$ \\
\hline
\end{tabular}


Table 2. (cont.) Blood serum laboratory investigation.

\begin{tabular}{l|ll}
\hline \multicolumn{1}{c|}{ Serum } & Normal value & \multicolumn{1}{c}{ Result } \\
\hline Lipid profile & & \\
• Cholesterol & $\bullet<5.21$ & $\bullet 5.98$ \\
- High density lipoprotein & $\bullet 0.9-1.45$ & $\bullet 0.91$ \\
• Low density lipoprotein & $\bullet<4.12$ & $\bullet 3.90$ \\
- Triglycerides & $\bullet<2.0$ & $\bullet 4.5$ \\
\hline Liver function test & & $\bullet 40$ \\
- Albumin serum & $\bullet 40-49$ & $\bullet 98$ \\
- Alkaline phosphate & $\bullet 40-130$ & $\bullet 30$ \\
- ALT/GPT & $\bullet<41$ & $\bullet 26$ \\
- AST/GOT & $\bullet<40$ & $\bullet 2.60$ \\
- Direct bilirubin & $\bullet<5$ & $\bullet 8$ \\
- Total bilirubin & $\bullet<21$ & \\
\hline
\end{tabular}

Table 3. Echocardiogramresult.

\begin{tabular}{l|l}
\hline $\begin{array}{l}\text { Left ventricle } \\
\text { Left atrium }\end{array}$ & $\begin{array}{l}\text { Regional wall motion abnormality noted in inferoposterior wall } \\
\text { (basal to apical). Overall normal systolic function at 56\%. } \\
\text { Normal size. }\end{array}$ \\
Aortic valve & $\begin{array}{l}\text { Structurally normal. No regurgitation or stenosis. } \\
\text { Structurally normal. No regurgitation or stenosis. }\end{array}$ \\
Mitral valve & $\begin{array}{l}\text { Dilated with good systolic function. } \\
\text { Right ventricle }\end{array}$ \\
Right atrium & Normal size. \\
Tricuspid valve & Structurally normal. No regurgitation or stenosis. \\
Pulmonic valve & Structurally normal. No regurgitation or stenosis. \\
Aortic arch & Normal. \\
\hline
\end{tabular}


This coronary angiography procedure (Table 4) injected the right coronary artery with X-ray contrast dye to show blockage or narrowing of the artery. A minor atheroma was seen distally from the left anterior descending coronary artery while a mid-tubular atheroma was visualized on the 1 st diagonal proximal segment of the coronary artery.

\section{METHODOLOGY}

The method of nursing care for this patient starts with a physical assessment. This assessment is necessary to develop a nursing care plan to provide care (Table 5). The activities in the ward found in the appendices enumerate the medications provided and the details of the vital signs monitored hourly. The method ends with a transfer out of the word.

\section{Physical Assessments}

Mr. F's general conditions were assessed to be fully conscious, awake, alert, communicating well and follow commands, able to move all limbs with a total Glasgow Coma Scale (GCS) score of 14/15. Mr. F's initial vital signs are:

- BP: $130 / 90 \mathrm{~mm} \mathrm{Hg}$

- Pulse Rate: 92/min

- Shortness of breath, respiratory rate: 19 / minute

- Chest pain with visual analogue scale (VAS) score of $7 / 10$

- RBS: 139 mmo 1; and

- SPO2: 97\% on room air.

No complaints of nausea or vomiting noted. Output was at $600 \mathrm{mls}$ of urine for the first 6 hours, while the total intake calculated was $731 \mathrm{mls}$ within 6 hours. Within normal range of respiratory rates, there were no signs of lung atelectasis; while the Sp02 was maintained at $98 \%$.

However, there were anxiety and facial grimacing noted in combination with shortness of breath, fatigue, and fresh and clammy skin when touched. Palpitation, weak pulse, and jugular vein distention were also observed.

Table 4. Coronary angiography results.

\begin{tabular}{l|l}
\hline Left main stem & $\begin{array}{l}\text { Normal } \\
\text { Left anterior descending }\end{array}$ \\
1st diagonal & $\begin{array}{l}\text { Mild-tubular disease in the proximal segment } \\
\text { Nircumflex }\end{array}$ \\
Right coronary artery & $\begin{array}{l}\text { Domid-vessel disease } \\
\text { moderate tandem lesion (culprit vessel) }\end{array}$ \\
\hline
\end{tabular}




\section{Nursing Care Plan}

The goal is to reduce the pain (from $7 / 10$ to 2/10) within 8 hours of nursing care. Therefore, the priority nursing diagnosis would be "acute pain related to decrease in myocardial blood flow" (Doenges et al. 2014). Buck (2012) and Doenges et al. (2014) stated that severe pain due to the myocardium's infarct impeding blood flow was one of the causes of deaths worldwide due to an ischemic heart disease.

Which is why the primary nursing intervention is to assess the vital signs such as the VAS, the facial grimacing, irritability, hypertension, shortness of breath and palpitations. Noting onset, duration, location and pattern of pain is also necessary. This will differentiate angina pain from other referred pains. The pain was monitored hourly (Appendix 2). Secondly, oxygenation was provided to relax the myocardial muscles. It is also important to stay with the patient to decrease the anxiety that may increase myocardial workload. Complete bed rest were instructed and maintained the head of the bed on moderate high back rest at $45^{\circ}$ angles to reduce myocardial oxygen demand. Reducing preload and afterload of the heart reduces pain. The rationales for the nursing interventions are enumerated in Table 5.

Medications, on the other hand, are dependent nursing actions that require licensed physicians' orders. However, it is also important to methodological plan for the nursing responsibilities before administering the drugs.

\section{Drug Study}

Details of drug dosages, frequencies, and side effects are found in Appendix 3. Platelet aggregation inhibitors were Juspirin and Clopidogrel Plavix (both orally administered).
However, these drugs will only be used after the percutaneous coronary intervention to avoid bleeding during the procedure (Davi's Drug Guide 2000-2016). The nursing responsibility when administering these drugs is to frequently monitor bleeding gums and episodes of hematuria as the patient is ambulatory and performs activities of daily living as he wishes to. It is also important to avoid proton pump inhibitors since it may lead to reinfarction and revascularization (Vera 2013). Besides lung sounds, depth of breathing and respiratory rate may also be monitored to ensure that oxygenation is not compromised if Morphine are given for pain (Vera 2012; Drugs.com 2000-2016).

Heart drugs on the other hand were Concor $^{\circledR}$, ramipril, and morphine used for chest pain and hypertension (Mays 2013). The significant responsibility indicated for the patient is to monitor electrocardiography, pulse rate and blood pressure (Vera 2013; Vera 2012). These drugs are necessary before commencing with percutaneous coronary intervention as it stabilizes the heart muscles and ensures that the heart remains pumping even after the procedure (Davi's Drug Guide 2000-2016; Drugs.com 2000-2016).

Lastly, the drugs used for cholesterol were Lipitor $^{\circledR}$ and lipantyl. It is important to remove this lipoprotein as it is dangerous for the heart muscles to be covered with lipids (Davi's Drug Guide 2000-2016). Monitoring of blood sugar is also vital since these drugs may induce hypoglycemic episodes to those who are on NPO (Davi's Drug Guide 2000-2016).

\section{Transfer Out of the Word}

Transferring patient out of an intensive care unit such as the coronary care unit is an evidence of 
a successful nursing care. After the procedure, Mr. F stayed overnight in Coronary Care Unit and was referred to a hospital dietitian, and heart specialists for rehabilitation. The rehabilitation programme will be continued in Telemetry Ward and will be instructed to adhere to the treatments until discharged. Also the nutritional status was assessed prior to ward trans-out. Mr. F was diagnosed at high nutritional risk due to compromised glucose level after NPO and was aggravated by anticoagulants and continuous prescriptions of 3-hydroxy-3-methylglutarylcoenzyme (HMG-CoA) reductase inhibitors (such as Lipitor). It was suggested that a cardiac Diabetic Mellitus diet is to be taken.

Recent laboratory results (including the percutaneous coronary intervention techniques) were also endorsed to the receiving nurse in charge at the regular ward. The blood investigation results were: Hgb: 12; Mono: 7.90 (high); MPV:11.1(high); Chol: 5.98 (high); CL: 97 (low); HbA1c: 96 (high); HDL: 0.83 (low); TG: 6.6 (high); and Trop-I: 0.423.

Since general conditions and vitall signs were stable, Mr. F was transferred out to Telemetry Unit on 11 August 2016 at $1500 \mathrm{H}$.

\section{Post-discharge Follow-up}

Effective communication and therapeutic relationship with the patient and their family increase long-term compliance with lifestyle adapt and prescribed drugs. At discharge, patient should have received details regarding medication, diet, exercise, smoking cessation counseling, referral to cardiac rehabilitation prevention programmes. Low risk and a revascularized patient should given appointment to come back within 2-6 weeks and higher risk within 14 days.

\section{DISCUSSION}

This section will discuss the demography of the patient; and will rationalize why such profiles were mainly acquired to study his case.

The patient was a smoker. Smoking is the most risk factor for heart disease (Dioso 2015; Mohan et al. 2008; Zubaid et al. 2009). Smoking can cause high blood pressure, lipids worsen, and make a very sticky platelets, raising the risk of clots (ACLS Institue 2016). Smoking is often practiced by men than women (Dioso 2015). Meanwhile, heavy cigarette smokers are at substantial risk for a blood vessel influential defect that exposes danger to the heart (McPherson et al. 2011; Vincent et al. 2011).

The patient was also hyperlipidemic, diabetic and hypertensive. Zubaid et al. 2009 explained that myocardial infarction is associated due to the high usualness of cardiovascular risk factors, such as diabetes mellitus, hypertension, smoking, and hyperlipidemia; which resulted from notable changes in the lifestyle behaviors; such as decrease exercise and poor dietary habits. In Saudi Arabia known as the "generation of electronic potatoes", a 1 in 4 people are meant to be possibly afflicted with fatal heart attacks within ten years (Zubaid et al. 2009; AlHabib et al. 2011). In retrospect, more than 4,900 Saudi, majorities of age between 20 to 40 years old who do not have a history of heart disease and lived in large urban areas like Riyadh, $26 \%$ experienced heart attack due to obesity and diabetes complications (Zubaid et al. 2009). Dr Adil Soofi explained that the cause of heart attacks is because of the practice of unhealthy lifestyle from an early age. He said, "they like to eat fast food and fried and greasy foods and lacks exercise." Atherosclerosis, 


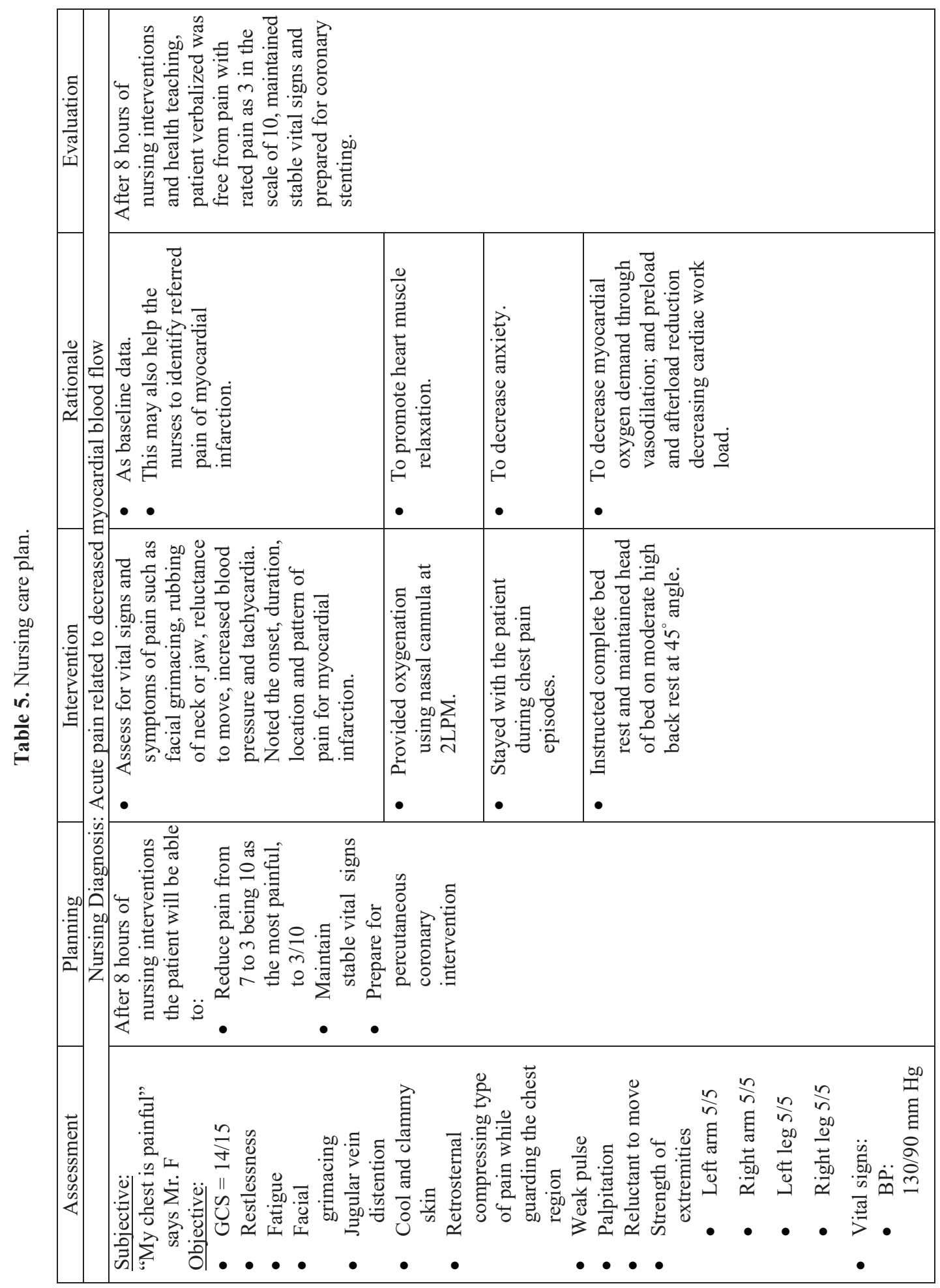




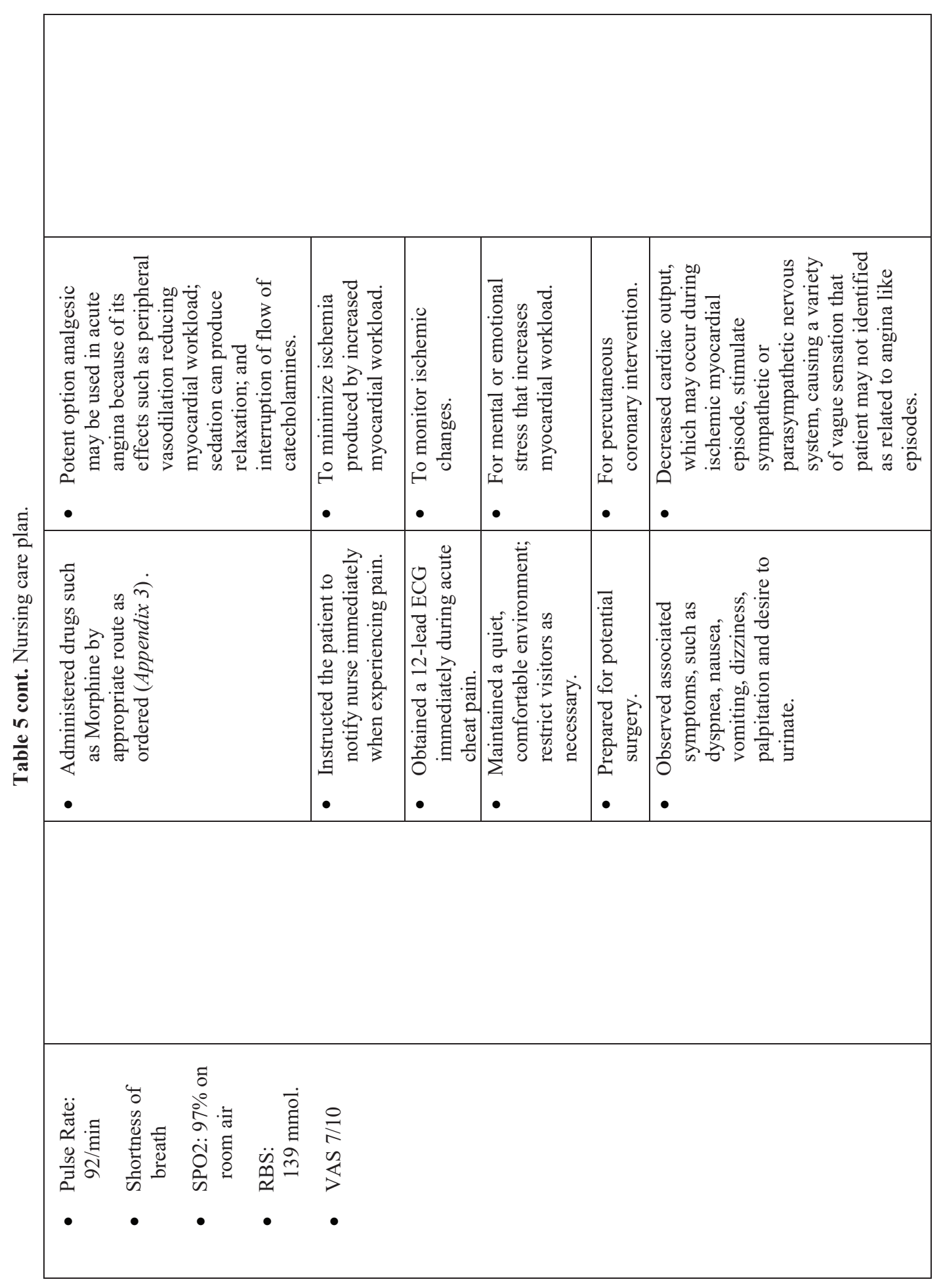


obesity and other risk factors in Saudi have been identified as one of the factors leading to early heart attacks and even death at a young age (Zubaid et al. 2009; Richardson 2015). The study done by The Saudi Project for Assessment of Coronary Events from December 2005-2007 found $72 \%$ were either overweight or obese. Overweight and obese patients were significantly younger than the normal-weight group $(\mathrm{P}=0.006)$. In general, obesity prevails throughout the world which is found that $33.1 \%$ and $32.2 \%$ of Americans were overweight and obese (McPherson et al. 2011).

Meanwhile, men are more at risk of having coronary artery disease because in general, a woman lived longer than men (ACLS Institute 2016; Harris 2006). Men also appear like engaging in stressful behaviour (Mohan et al. 2008; Badimon et al. 2012). Mobeirek et al. 2014; Hersi et al. 2013; and Harris 2006 argued that all of the various stress have been relevant with higher fatal risks of coronary heart disease.

\section{CONCLUSION}

Mr. F was sent to cardiac catheter laboratory at $1030 \mathrm{H}$. From the cardiac catheter laboratory post-percutaneous coronary intervention to the mid-right coronary artery (1 Drug-Eluting Stent) he was transferred out to Telemetry unit on 11 August 2016 at $1500 \mathrm{H}$ with Terumo band hemostatic device through radial approach.

In conclusion, the factors that trigger myocardial infarction is the unhealthy lifestyles such as consumption of fatty foods, oily, salty, fast food and so on, which led to Mr. F to suffer from a heart disease. Also other factors are identified that are less encouraged such as stress at work and the possibility of a lazy lifestyle. Mr. F denied that he had diabetes but the
RBS (120-139 mmol/l) and HBA1C (6.96\%) revealed it. The amount of fat contained is more than ideal body weight of the patient. Therefore dietician was recommended. There are several things in the rehabilitation programme that have also been recommended for Mr. F to take and practice to improve his lifestyle.

\section{RECOMMENDATION}

As recommended by NSTEMI (2014) guidelines for the management of patients of NSTEMI is as follow:

1. Adhere to treatment modalities of; and

2. Ensure that the patient is instructed about how to modify cardiac risk factors (as shows below).

\section{Smoking Cessation}

Patient should be advised to quit smoking and avoid exposure to environmental tobacco smoke at home, work or at public places. Patient was recommended for counseling and plan development for quitting, including nicotine replacement and referral to special smoking cessation programme. The patient should be referred to smoking cessation programme after one month of hospitalization.

\section{Optimal Weight}

Patient should be encouraged to maintain his body mass index at normal range. The initial target is to reduce body weight by approximately 5-10\% from baseline. Diet and exercise is a combination that should be done.

\section{Daily Exercise}

A month of post-NSTEMI events, should be favourable to perform 30-60 minutes of exercise for seven days a week to improve heart 
function, body function, reduce cardiac risk factors, reduce risk of a second heart attack and improve psychological well being. Rigorous exercise and lifting heavy objects are prohibited and taken with caution.

\section{Diet}

Low intake of salt and saturated fats, and regular intake of fruits, vegetables and fish would be a perfect recommendation. Mediterranean diet has been taken as a model for optimum mental and physical fitness. However, taking moderate wine and alcohol should not be encouraged.

\section{Blood Pressure Control (<140/90 mm Hg)}

Counseling of lifestyle adjustment is needed to create the conditions for optimal blood pressure management. It involves a number of things that need to be practiced such as weight control, increased physical activity, alcohol moderation, salt reduction and greater consumption of fresh fruits, vegetables and low fat dairy products. If the blood pressure exceed the limits, pharmacological therapy with beta blockers and/or angiotensin-converting enzyme inhibitors or angiotensin-receptor blockers should be commence, with the introduction of other drugs such as calcium channel blockers or thiazides diuretics as needed to attain the treatment objective.

\section{Consider Referring an Out Patient Cardiac Rehabilitation Programme}

This gives a comprehensive long-term programme that limits physiological and physiological impact of cardiac illness by involving medical evaluation, prescribed exercise, lifestyle and cardiac risk factor modification, education and counseling. Exercise may include bicycle, treadmill, calisthenics, walking and jogging. Patients should be given specific instruction on activities (e.g. lifting, climbing stairs, and household activities) that are allowable and avoided. Particular state should be made of resumption of driving, return to work, and sexual activity.

\section{REFERENCES}

ACLS Institute 2016, 'Morphine', <https://acls. $\mathrm{com} /$ free-resources/medication-medicationdelivery/morphine>.

AlHabib, K H, AlFaleh, A, AlNemer, H \& AlSaif, K 2011, 'S. Baseline characteristics, management practices, and in-hospital outcomes of patients with acute coronary syndromes: results of the Saudi project for assessment of coronary events (SPACE) registry', Journal of the Saudi Heart Association, vol. 23, no. 4, pp. 233-239.

Anderson, JL Adams, CD, Antman, EM, Bridges, CR Califf, RM \& 2011, 'ACCF/ AHA focused update Incorporated into the ACC/AHA 2007 guidelines for the management of patients with unstable angina/non ST-elevation myocardial infarction', The American College of Cardiology Foundation/American Heart Association Task Force on Practice Guidelines, Circulation, (Published online March 28, 2011).

Badimon, L., Padró, T \& Vilahur, G 2012, 'Atherosclerosis, platelets and thrombosis in acute ischemic heart disease. NCBI', $<$ http://www.ncbi.nlm.nih.gov/pmc/articles/ PMC3760546/>.

Buck, CJ 2012, Step-by-step medical coding, Elsevier Health Sciences, 11 Dec $2012-$ Medical, <https://books.google.com>.

Davi's Drug Guide 2000-2016, 'Unbound Medicine Inc.', <http://www.drugguide. com/ddo/ view/Davis-Drug-Guide/51518/ all/morphine $>$. 
Dioso, R. (11) 2014, 'Cigarette smoking among male teenagers in Malaysia: a narrative review', ASEAN Journal on Science and Technology for Development, vol. 31, no.1, pp.24-30.

Doenges, ME, Moorhouse, MF \& Murr, AC 2014, 'Nursing care plans: guidelines for individualizing client care across the life span', ed. FA Davis, 7 March 2014 Medical, < https://books.google.com>.

Drugs.com 2000-2016, 'Morphine sulfate injection. Dosage form: injection, solution', $<$ https://www.drugs.com/pro/morphinesulfate-injection.html>.

Granato, JE 2011,'Living with coronary heart disease: a guide for patients and families', JHU Press, 1 Jun 2011 —Health and Fitness, $<$ https://books.google.com>.

Harris, CR 2006, 'Gender differences in risk assessment: why do women take fewer risks than men?', Judgment and Decision Making,vol. 1, no. 1, pp. 48-63. Michael Jenkins University of California, San Diego and Dale Glaser, Glaser Consulting Firm, San Diego,<http://journal.sjdm.org/ jdm06016.pdf $>$.

Hersi A, Al-Habib K, Al-Faleh H, Al-Nemer K, Alsaif S, Taraben A, Kashour T, Abuosa AM \& Al-Murayeh MA 2013, 'Gender inequality in the clinical outcomes of equally treated acute coronary syndrome patients in Saudi Arabia', NCBI, Ann. Saudi Med., vol. 33, no. 4, pp. 339-346, doi: 10.5144/02564947.2013.339, <https://www.ncbi.nlm.nih. gov/ pubmed/24060711>.

Kipshidze, N, Fareed, J, Rosen, RT, Dangas, G, Serruys, P 2014, Urgent interventional therapies', chap. 20, Management of patients after acute coronary syndrome, John Wiley \& Sons. Medical, <https://books. google.com>.
Levy, MR, Dignan, MB, Shirreffs, JH, McGraw, H 1992, 'Life and health:targeting wellness', vol.1, Health and Fitness, <https://books. google.com>.

Mays, JA 2013, Prescription medication/ drug misuse and abuse: a clear and present danger, Xlibris Corporation, Education, $<$ https://books.google.com>.

McPherson, RA. \& Pincus, MR 2011, 'Henry's clinical diagnosis and management by laboratory methods', 2. Clinical chemistry: cardiac injury, atherosclerosis and thrombotic disease, Elsevier Health Sciences, Medical-1568, <https://books. google.com>.

Mohan, C, Madala, BA, Franklin, AY, Chen, AD \& Berman, MD 2008, 'Obesity and age of first non-st-segment elevation myocardial infarction', Journal of the American College of Cardiology, vol. 52, no. 12, <//content. onlinejacc.org/pdfaccess.ashx?ResourceID= 2922506\&PDFSource $=13>$.

Mobeirek AF, Al-Habib K, Al-Faleh H, Hersi A, Kashour T, Ullah A, et al. 2014, 'Absence of obesity paradox in Saudi patients admitted with acute coronary syndromes: insights from SPACE registry', Ann. Saudi Med., vol. 34, no.1, pp. 38-45, http:// www.annsaudimed.net/index.php/vol34/ vol34iss1/668.html>.

NSTEMI 2014, <http://nstemi.org/>.

Richardson, H 2015, 'One in four young Saudis at risk of heart attack, study warns', Newsweek (13 February 2015), <http://www. newsweek.com/one-four-young-saudis-riskheart-attack-study-warns-306613>.

Shehab A, Al-Dabbagh B, AlHabib KF, Alsheikh-Ali AA, Almahmeed W \& Sulaiman K 2013, 'Gender disparities in the presentation, management and outcomes of 
acute coronary syndrome patients: data from the 2 nd Gulf registry of acute coronary events (Gulf RACE-2)', <http://journals.plos.org/ plosone/article?id=10.1371\%2Fjournal. pone.0055508>.

Vincent, J, Abraham, E, Moore, FA, Kochanek, P \& Fink, MP 2011, Textbook of critical care, 6 edn. Part 4, Cardiovascular, acute coronary syndromes: therapy, Elsevier
Health Sciences, Medical $<$ https://books. google.com>.

Vera, M 2013, '4 angina pectoris (coronary artery disease) nursing care plans', Nurseslabs., $<$ http://nurseslabs.com/morphine-sulfatedrug-study/>.

Vera, M 2012, Morphine sulphate drug study', Nurseslabs., <http://nurseslabs.com/ morphine-sulfate-drug-study/>.

\section{Appendix: Activities done in the ward}

1. Electrocardiograph.

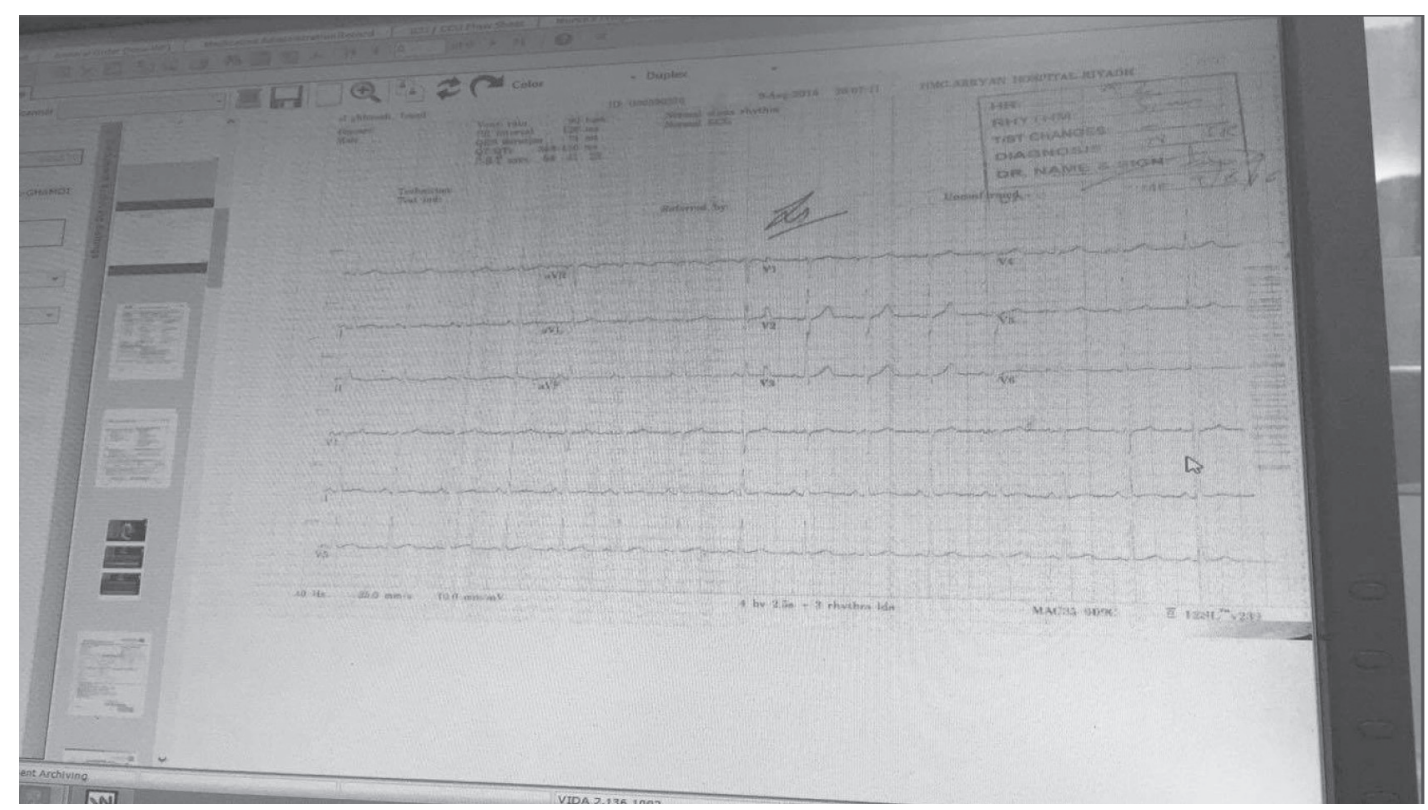


2. First eight hours monitoring of vital signs.

\begin{tabular}{c|ccccccc}
\hline Date/Time & Temperature & Pulse & RR* & $\begin{array}{c}\text { Blood } \\
\text { pressure }\end{array}$ & SPO2* & $\begin{array}{c}\text { Capillary } \\
\text { blood glucose }\end{array}$ & $\begin{array}{c}\text { VAS* pain } \\
\text { score }\end{array}$ \\
\hline $\begin{array}{c}10 / 08 / 2016 \\
0040 \mathrm{H}\end{array}$ & 36.6 & $92 / \mathrm{min}$ & $21 / \mathrm{min}$ & $122 / 80 \mathrm{~mm} \mathrm{Hg}$ & $97 \%$ & $139 \mathrm{mmol} / 1$ & $7 / 10$ \\
$0140 \mathrm{H}$ & 36.5 & $94 / \mathrm{min}$ & $20 / \mathrm{min}$ & $120 / 75 \mathrm{~mm} \mathrm{Hg}$ & $98 \%$ & $138 \mathrm{mmol} / 1$ & $7 / 10$ \\
$0230 \mathrm{H}$ & 36.3 & $100 / \mathrm{min}$ & $30 / \mathrm{min}$ & $140 / 88 \mathrm{~mm} \mathrm{Hg}$ & $93 \%$ & $137 \mathrm{mmol} / 1$ & $7 / 10$ \\
$0245 \mathrm{H}$ & 36.4 & $98 / \mathrm{min}$ & $28 / \mathrm{min}$ & $135 / 78 \mathrm{~mm} \mathrm{Hg}$ & $94 \%$ & $136 \mathrm{mmol} / 1$ & $6 / 10$ \\
$0300 \mathrm{H}$ & 36.5 & $94 / \mathrm{min}$ & $26 / \mathrm{min}$ & $130 / 80 \mathrm{~mm} \mathrm{Hg}$ & $95 \%$ & $135 \mathrm{mmol} / 1$ & $6 / 10$ \\
$0330 \mathrm{H}$ & 36.5 & $96 / \mathrm{min}$ & $24 / \mathrm{min}$ & $132 / 82 \mathrm{~mm} \mathrm{Hg}$ & $96 \%$ & $134 \mathrm{mmol} / 1$ & Asleep \\
$0400 \mathrm{H}$ & 36.6 & $90 / \mathrm{min}$ & $20 / \mathrm{min}$ & $128 / 76 \mathrm{~mm} \mathrm{Hg}$ & $95 \%$ & $133 \mathrm{mmol} / 1$ & Asleep \\
$0430 \mathrm{H}$ & 36.8 & $93 / \mathrm{min}$ & $19 / \mathrm{min}$ & $136 / 70 \mathrm{~mm} \mathrm{Hg}$ & $96 \%$ & $132 \mathrm{mmol} / 1$ & Asleep \\
$0500 \mathrm{H}$ & 36.7 & $75 / \mathrm{min}$ & $18 / \mathrm{min}$ & $118 / 70 \mathrm{~mm} \mathrm{Hg}$ & $96 \%$ & $130 \mathrm{mmol} / 1$ & Asleep \\
$0530 \mathrm{H}$ & 36.6 & $85 / \mathrm{min}$ & $21 / \mathrm{min}$ & $120 / 80 \mathrm{~mm} \mathrm{Hg}$ & $97 \%$ & $125 \mathrm{mmol} / 1$ & Asleep \\
$0600 \mathrm{H}$ & 36.5 & $80 / \mathrm{min}$ & $20 / \mathrm{min}$ & $122 / 75 \mathrm{~mm} \mathrm{Hg}$ & $98 \%$ & $120 \mathrm{mmol} / 1$ & Asleep \\
$0700 \mathrm{H}$ & 36.4 & $88 / \mathrm{min}$ & $20 / \mathrm{min}$ & $110 / 70 \mathrm{~mm} \mathrm{Hg}$ & $97 \%$ & $140 \mathrm{mmol} / 1$ & $3 / 10$ \\
\hline
\end{tabular}

$* \mathrm{RR}=$ Respiratory rate; SP02 $=$ Saturated partial oxygenation; VAS $=$ Visual analogue scale

\section{Medications}

\begin{tabular}{|c|c|c|c|c|}
\hline \multicolumn{5}{|c|}{ Drug study } \\
\hline Drugs Names & Dosage & Frequency & Indication & Side effects \\
\hline Plavix & $75 \mathrm{mg} / \mathrm{tab}$ & Once a day & Blood clot & Blood-tinged urine \\
\hline Concor & $10 \mathrm{mg} / \mathrm{tab}$ & Once a day & Chest pain & $\begin{array}{l}\text { Mild headache, and skin } \\
\text { rashes }\end{array}$ \\
\hline Ramipril & $5 \mathrm{mg} / \mathrm{tab}$ & Once a day & Hypertension & Dizziness and nausea \\
\hline Lipitor & $40 \mathrm{mg} / \mathrm{tab}$ & Once a day & Cholesterol & $\begin{array}{l}\text { Dark colored urine; } \\
\text { hypoglycemia }\end{array}$ \\
\hline Lipantyl & $145 \mathrm{mg} / \mathrm{tab}$ & Once a day & Triglyceride & Hypoglycemia \\
\hline Juspirin & $81 \mathrm{mg} / \mathrm{tab}$ & Once a day & Clotting & Discoloration of urine \\
\hline Morphine & $\begin{array}{l}3 \mathrm{mg} \\
\text { intravenous }\end{array}$ & As necessary & Chest pain & Drowsiness \\
\hline
\end{tabular}

